\title{
Antecedentes Icónicos de nuestra Historla Educatlva: Preámbulo para la Reflexión sobre una filosofía de la Educación
}

\author{
Por: Oscar Picardo Joao

\begin{abstract}
"Tenemos que criticar que la educación, por lo general en América Latina, no corresponde a la necesidad de unos pueblos que buscan su desarrollo. Es una educación que tiene un contenido abstracto, formalista, una didáctica más preocupada de transmitir conocimientos que de crear un espiritu critico"
\end{abstract}

I presente ensayo intenta reflejar de un modo más icónico el acontecer educativo en el devenir histórico de El Salvador; se trata de un análisis genérico y revisionista a modo de preámbulo, que da pautas para comprender los problemas del presente. En este contexto y desde esta perspectiva se observan las influencias imperialistas de la España conquistadora y colonial (espada y cruz), y de los Estados Unidos con sus intentos hegemónicos urilitarios y pragmáticos; así mismo, se describen algunos hitos y tópicos de la educación salvadoreña en la primer a mitad del siglo XX.

Sin lugar a dudas las influencias Española y Norteamericana ${ }^{2}$, respectivamente, han incidido significativamente en nuestro sistema educativo nacional; tema que debe ser estudiado $y$ analizado para comprender el acontecer actual. En efecto, como afirmaba Bloch "la incomprensión del presente, nace fatalmente de la ignorancia del pasado".

Con el presente artículo intentamos escudriñar sobre la abiogénesis que fraguó y marcó el destino de la educación en la región centroamericana, y concretamente en EI Salvador, para luego pensar en una posible agenda contemporánea que responda a las necesidades y problemas de una Filosofia Educariva.

Veamos primero la influencia de "La cruz y la espada" de la Corona Española; a juicio del intelectual mexicano
Leopoldo Zea en su obra "América como aurodescubrimiento" "lo que sucedió en el mal Ilamado descubrimiento fue un verdadero "tropezón", en donde los influjos de la etapa histórica dominante colonialista de los siglos XV y XVl, cuyo origen se encuentra en la Florencia de los Medici llegó a los paises mediterráneos; en efecto, el renacimiento a España llegó de modo tardio, pero llegó, debido a su fidelidad a la ortodoxia católica, y en este pais en donde la Santa Inquisición se ubica tras la corona abarcando los dominios monárquicos de cada Virreinato, Capitanía y Colonia.

\section{La conquista española}

F n este contexto, España colonializa bajo los signos de Cla Espada y de la Cruz, es decir colonializa y análogamente evangeliza, pero estas dos acciones van hilvanadas por evidentes signos de violencia, bajo el adagio de Tucidides: "la violencia no solo es la causa de todas las guerras sino también el método rápido para la expansión de las civilizaciones": pero esta violencia tiene tres características muy suyas: a) existen diáfanos mandatos politicos que las justifican; b) se justifica ante las rebeldias de creencias extrañas; $y$ c) rienen la bendición o están sacralizadas por la iglesia; en el fondo el temerario inquisidor Fray Tomás de Torquemada, con la biblia bajo el brazo def endía la tesis en donde solo admitia tres clases de seres humanos: jaf etitas (negros), semiticos (asiáticos) y camíticos (arios). 


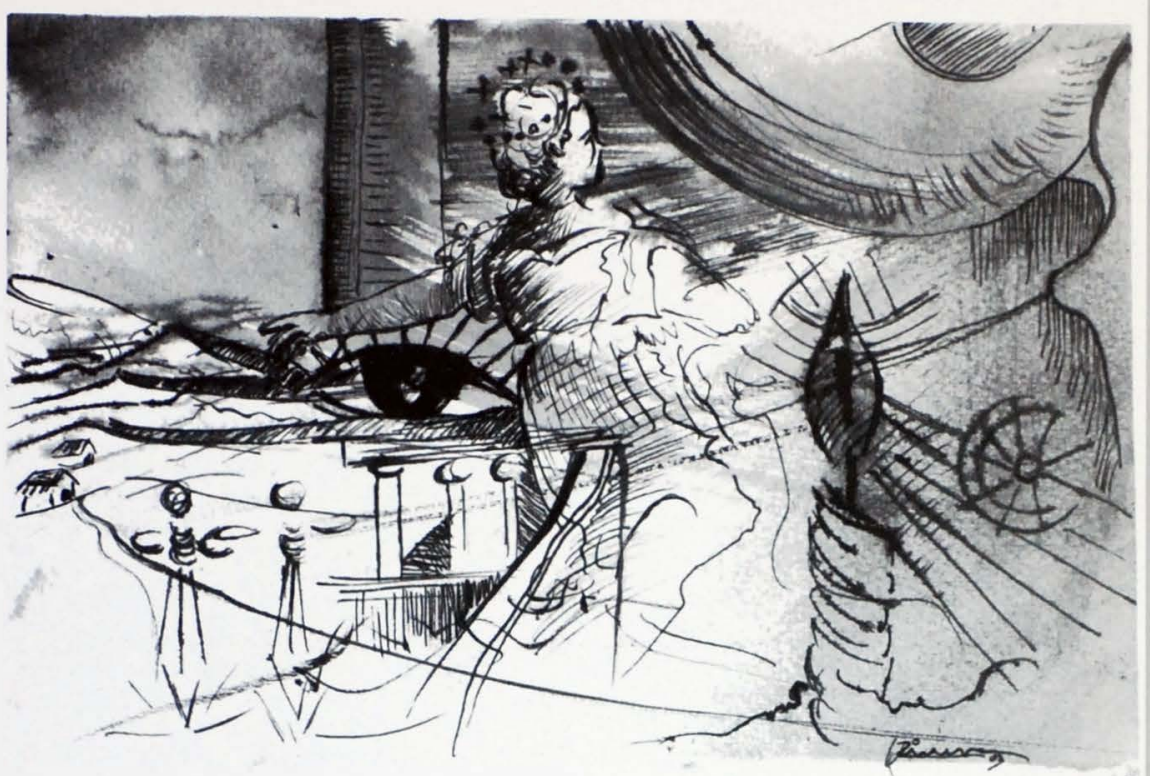

De hecho pasaron más de 30 años para que la iglesia se dignara aceptar que los autócronos eran verdaderas personas, a través de la Bula de Paulo III en 1537, después de un arduo debate entre los frailes Sepúlveda y de las Casas.

La Encomienda y el Repartimiento, la sed del oro y la esclavitud bosquejaron insritucionalmente dos formas de propiedad: las tiertas y los seres humanos que vivían en dichas tierras, bajo un imaginario de crueldad indescriptible.

Con la encomienda se instirucionalizó un circulo de evangelización, a pesar de algunas concepciones nefastas como la citada por Eduardo Galeano: "en 1557, un miembro del real consejo le respondió (al padre Las casas) que los indios estaban demasiado bajos en la escala de la humanidad para ser capaces de recibir la fe"s.

Pasó así la conquista entre violencias y vejámenes y llegó la Colonia como un largo período político para la consolidación del poder peninsular y su enriquecimiento, en donde se fraguaron abundantes rebeliones, por lo que fue necesario construir la Ley de la igualdad entre el indio y el español', la cual no fue acatada ni cumplida inmediatamente; las dos cosmovisiones, las dos culturas no podian compartir el tiempo ni el espacio, y solo con el mestizaje se fue asimilando li nueva lengua y el nuevo credo.

\section{EI mestizaje en EI Salvador}

E. Ifenómeno del mestizaje contó con una buena dosis de una forma social y psicológica de realización imaginaria de deseos; aquello que no podian hacer y por lo que les castigaban, se traducia en mitos y leyendas y en algunos personajes reales que caralizaban las necesidades.

En El Salvador, la constitución demográfica es mestiza, existen muy pocas familias que han conservado su naturaleza étnica de criollos o indigenas; el lento proceso del mestizaje se inició en los primeros dos siglos del dominio colonial; el español se mezcló con el indigena con gran facilidad, eliminando, casi cotalmente la estratificación racial, quedando más bien una estratificación social y económica.

David Browning y Barón Castro 6 aportan sustanciales datos de la composición demográfica y sobre los factores que inciden en su comportamicnto a través de nuevas prácticas y circunstancias, como por ejemplo la introducción del ganado, las nuevas patologias y los cambios de cultivos; estas modificaciones demográficas significativas afectan o aceleran 
los cambios culturales, el cambio de lengua y de religión impuesto, prepara las bases de un nuevo escenario social.

entorno entorno entorno entorno entorna entorno entorno entorno entorno entorng entorno entorno entorno entomo entorno entorno entorno entorno entorno entorno entorno entorno entorno entorno entorno entorno entorno entorino entorino entorno entorito entorino entorito entorito entorno sitorino entomo Gitorise entorne entorno entorino entorno entorno entorne entorne entorino entorno Enloino entEntorno ent220 बतिकितिए
El cambio de religión inició desde los inicios de la conquista subvirtiendo las creencias de los autóctonos a la fuerza; el cambio de la lengua también inició al mismo tiempo, pero en 1518 se emirió la orden real de Doña Juana en donde obliga a los encomenderos a alfaberizar a uno o dos indios de los más inteligentes, para que éstos reduplicaran la acción con su gente; se trataba pues, de una violencia institucional para imponer una nueva cultura occidental. Mientras el Ladino va emergiendo la lucha cultural se va desvaneciendo, pero las inseguridades económicas de indios y ladinos aceleran el proceso de transculturación española.

\section{La independencia de la colonia}

Don la independencia se cierra parcialmente el capítulo de la colonia quedando algunos vestigios naturales al sistema reformado; se da un cambio del régimen político $s i n$ modificar sustancialmente las estructuras económicas; en ef ecto, los movimientos emancipadores salen de los criollos, quienes controlan -junto a muy pocos ladinos- la producción y el comercio. Posteriormente la ortodoxia conservadora va perdiendo espacios ante el auge liberal, dando paso a las primeras empresas privadas de sectores comerciales y agroindustriales.
Tres sectores constituyen la composición demográfica de El Salvador postindependentista: criollos, ladinos $y$ minoritariamente indios; ya en 1841 cuando nace la Universidad de El Salvador comienza a emerger una clase media que se distancia de las concepciones tradicionales de clase, y de la única relación productiva existente hasta la fecha: hombre-tierra, emergiendo así tres modos de producción distintos y distantes: agricultura de subsistencia, agricultura de comercialización y nuevos oficios.

En términos muy generales, sobre esta etapa descrita, predominaron los esquemas católicos en los modelos educativos, bajo una acepción elitista que poco a poco fue descendiendo; en el fondo, el modelo educativo fue vertical, jerárquico, excluyente y teologizado, en donde la relación externa social configuraba el mapa del quehacer educativo; se trata de una cristalización de la obra "El pedagogo"de San Clemente, cuya característica es el ortodoxismo católico y la soberanía absoluta del maestro.

Este breve sinopsis nos presenta una antesala para comprender los ejes diseñados por Paulo Freire en su obra "La Pedagogín del Oprimido", "el ser menos" y "el ser más"; desde el punto de vista histórico de la producción nos encontramos con el español versus el indio, con el criollo versus el mestizo, con el terrateniente versus el campesino, con el patrono versus el obrero; siendo así, "el ser más" un

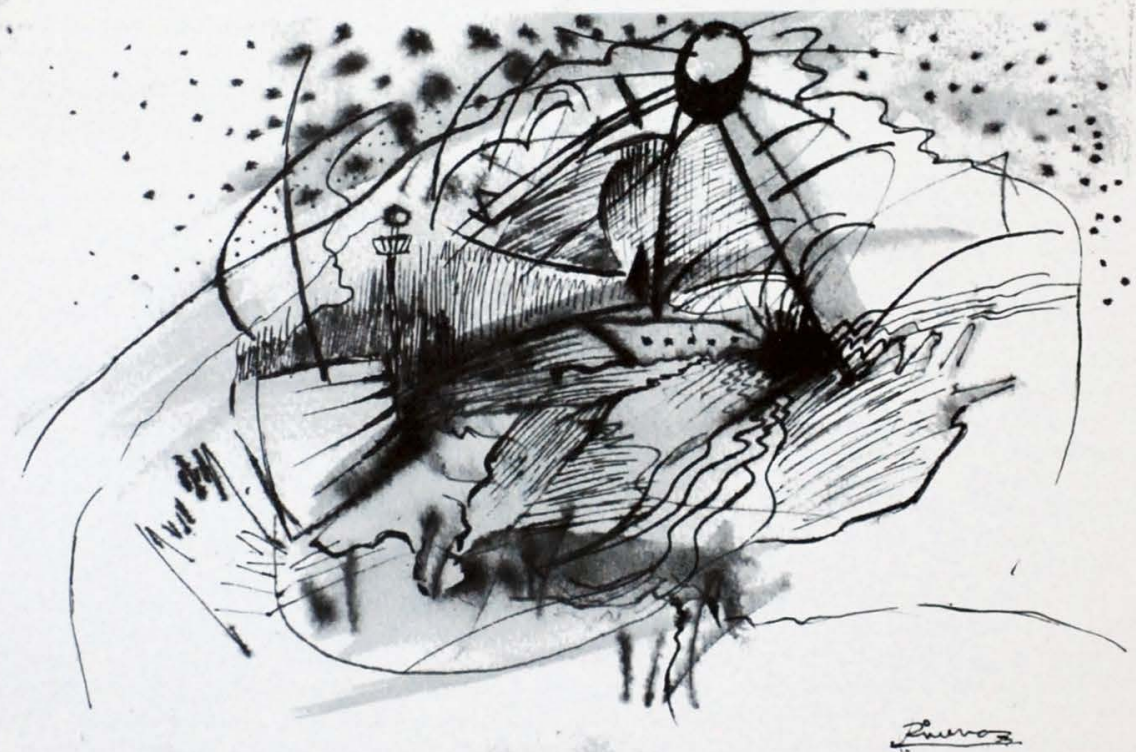


grupo minoritario, y el "el ser menos" ungrupo mayoritario, estructuralmente marginado.

\section{América para los americanos}

Ci la primera etapa la catalogamos como "espada y cruz", Ola segunda se puede llamar "América para los americanos". Las ideas ilustradas de influencia inglesa que llegaron a mediados del siglo XVII a América del Norte bosquejaron un escenario muy distinto; los principios empiristas de Locke, Berkley y Hume, junto a las ideas utilitaristas de Jeremias Bentham y John Stuart Mill, consolidaron una nueva visión social y producriva que podemos catalogar de "pragmatismo".

Para el pragmatismo, el mundo es explicable en sí mismo, es decir, objetivamente; el homo economicus de este escenario organiza y busca el bienestar, su destino es buscar el éxito y llegar a fines útiles de cara al desarrollo y a la conservación de la vida; estos principios más otra vertiente del enciclopedismo y la ilustración francesa dan la pauta para construir la Carta Magna en donde se solidifican las ideas para pensar en una sociedad norteamericana urilitarista y pragmárica.

La sociedad norteamericana se consolida sobre estratos sociales maduros provenientes de etnias europeas, sin ninguna incli-

En El Salvador, la constitución demográfica es mestiza, existen muy pocas familias que han conservado su naturaleza étnica de criollos o indígenas; el lento proceso del mestizaje se inició en los primeros dos siglos del dominio colonial; el español se mezcló con el indígena con gran facilidad, eliminando, casi totalmente la estratificación racial, quedando más bien una sola estratificación social y económica alla de lo económico, el interés era de carácter político estratégico, a modo de puntos presenciales de carácter militar para contrarrestar las oleadas de la amenaza comunista.

Pero tras está atmósfera cosmética existen otros nombres que iluminan un nuevo modo de ser norteamericano del siglo XX: Whitmann en la poesía y Mark Twain en la narrativa, quienes desde una plataforma de derechos civiles comienzan a atentar contra los prejuicios xenof óbicos.

Por otra parte, nos encontramos con "El Club Metafísico de Harvard" en donde aparecen los nombres de Chauncey Wright, nación a mezclarse con las etnias indígenas por razones estrictamente puritanas influidas por el protestanrismo: así los grupos étnicos indígenas se van reduciendo en las reservaciones hasta minimizar su presencia en las áreas de influencia aria y sajona. Ya para el siglo XIX las universidades de Harvard y Columbia consolidan su alto prestigio académico, en donde se educan las élites jóvenes de la nación, generándose un espectro social educativo de desborde con significativas consecuencias sociales.

En 1912 el Presidente William H. Taft dejó escritas la siguientes palabras: "Noestá lejano el día en que tres banderas de barras y estrellas señalen en tres sitios equidistantes la extensión de nuestro territorio: una en el Polo Norte, otra en el Canal de Panamá y la tercera en el Polo Sur. Todo el hemisferio será nuestro, como en virtud de nuestra superioridad racial, ya es nuestro moralmente" 7; así, Somoza
William james, Charles Peirce, John Fiske, John Dewey, entre otros, quienes depuran desde la academia la visión de país hacia un idealismo subjetivo, donde se acrisola el nuevo capitalismo de $\mathrm{fe}^{8}$ : si mi creencia me lleva al éxito puedo confiar en ella, si me lleva al fracaso debo encontrar otro punto en donde poner mi fe para arrancar de ahí con una nueva creencia.

Asimismo, Fiske en su libro "Ideas Políticas Americanas sostiene que: simplemente no hay historia, lo que existe es una evolución constante del hombre, guiada por su fe y su destino; $y$ asi como hay hombres superiores hay hombres inferiores, así también como los pueblos.

El pragmatismo de Peirce, de Wright y de Holmes se va a fortalecer con la nueva teoría de la historia de Fiske; lo que ahora se necesita es que estas ideas sean llevadas al sistema 


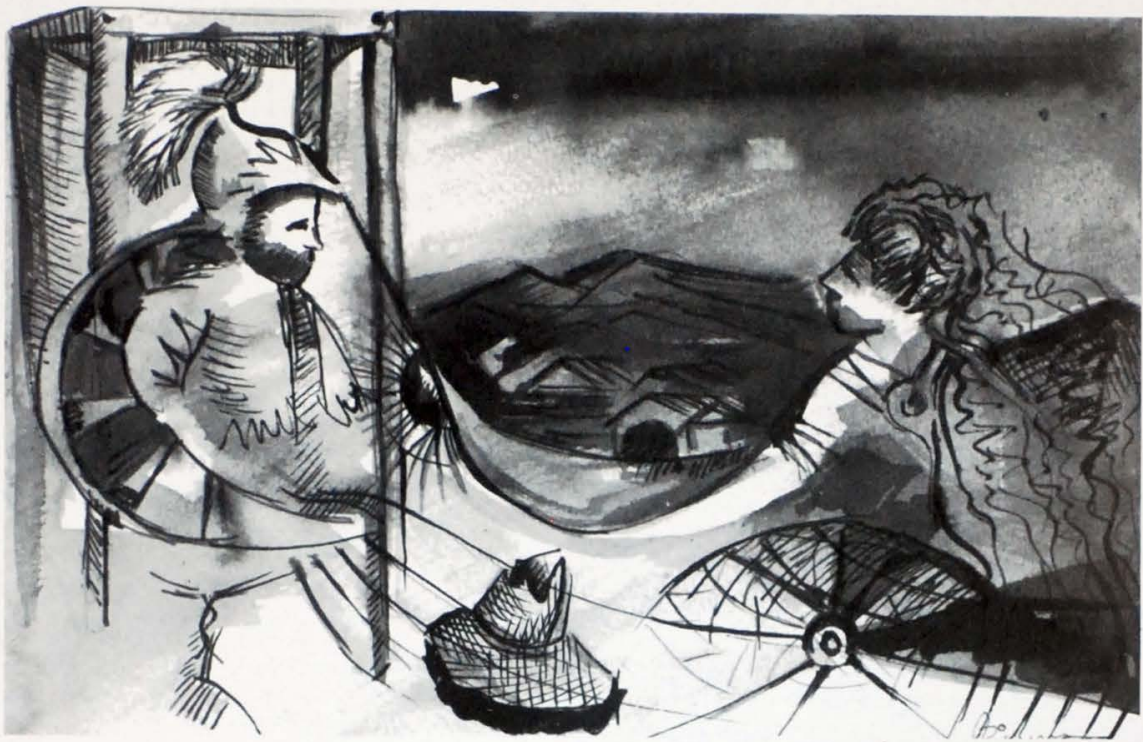

escolar para que de ahi salga el nuevo ripo de hombre que necesita el "Destino Manifiesto"; entonces era necesario crear una pedagogia para el superdotado, para quien la educación tendrá que ser abierta; $y$ una pedagogia para el simple espiritu prácrico del que no riene condiciones para el liderazgo; este es el papel que dentro del gran movimiento pragmático va a desempeñar Dewey.

Dewey es el representante de la filosofía que ha penetrado más profundamente en la formación de generaciones norteamericanas; quien además ha escrito numerosas obras" $y$ articulos sobre este tema, cuyas influencias han sido significativas en los esquemas de planificación educativa Latinoamericanos.

Dewey es considerado entre la era de los "activistas" pedagógicos, junto a Ferriere, Claparede, Bovet, Decroly, Montessori, cuyo origen se funde en "El Emilio" de JJ Rousseau, en donde se ubica al niño en el centro del hecho educativo; aqui el educador es considerado un "estimulador" y guia del niño: y el programa una realidad ordenada en complejidad crecience (estos son los tres componentes de acto educativo). Dewey tambićn asume las concepciones europeas de Froebel (la educación del hombre) y Haeckel (ley biogenética), pero en el fondo persisten las ideas de la educación para el éxito.
Con estas dos visiones influyentes que han dejado una huella, un estigma social y cultural podemos comprender las vertientes que surcan nuestro sistema educativo; se trata de tácitos y sutiles imaginarios que emergen en el quehacer educativo, aspectos que se cristalizan en la visión antropológica que el docente posee de si mismo y de los alumnos; ahora bien, veamos que ha acontecido después de estas influencias en EI Salvador.

\section{Una visión antropológica}

C n El Salvador, antes que nacieran las Escuelas Normales en dichas escuelas?; los educadores eran jóvenes bien adelantados en su formación básica, de modo especial en la lectoescritura, la gramática y el cálculo elemental; estos jóvenes, distinguidos en los estudios realizados, eran premiados con un nombramiento que proponian las Alcaldias a las Gobernaciones, bajo la autoridad del reglamento de Instrucción Pública de $1917^{10}$; el vivero de estos maestros eran algunos jóvenes, hijos de la pequeña burguesia rural aiiilera o ganadera, quienes hacian estudios en Guatemala, pudiendo estudiar, según su capacidad económica en el Colegio San Carlos, el San José de Calasanz o el Colegio Tridentino; al terminar el bachillerato, si por alguna razón no seguian los estudios universitarios en la 
Universidad de San Carlos volvían al país y se hacían nombrar maestros de escuela.

La formación más profesional de maestros en las Escuelas Normales comienzan bajo la administración del General Gerardo Barrios; posteriormente el general Francisco Menéndez contrató los servicios de cuatro colombianos para que dirigieran la educación ", y crearan un Plan de Educación general y formar el magisterio; cabe señalar que Colombia era escenario de una fuerte pugna entre liberalismo $y$ conservadurismo religioso, en donde el poder conservador era mayoritario.

Así pues, en América Latina y en Centroamérica se experimentó el debate educativo entre las corrientes liberales y religiosas conservadoras, e inmediatamente emergió la dicotómica visión de dos posturas; educación para el pueblo (educación del soberano, Domingo Faustino Sarmiento) o educación sistematizada y vertical; la educación culturizadora y la conquista de los grados académicos es el derecho de las clases dirigentes, y la educación alfabetizadora y artesanal, es la of erta que se hace al pueblo; pero en todo caso, ambas corrientes se preocuparon más por el Estado dejando el tema educativo en un segundo lugar de la agenda política.

\section{Educación para el pueblo}

ás tarde, emerge un nuevo punto de vista que trastoca 1 el rumbo educativo: "La Cuestión Social" 12; dicho concepto parte de la brecha existente entre los grupos sociales polarizados, concretamente a partir de las diferencias $y$ posibilidades culturales $y$ educativas, $y$ de su respecriva forma de vivir.

Aquí, por ejemplo, sale a la vista el asunto del analfabetismo vinculado a los altos índices de pobreza; esta dicotomía manifiesta el distanciamiento de un gruposocial de los valores de equidad, igualdad y justicia. Las diferencias individuales no pueden ser ignoradas por ninguna ideología; por eso Marx califica a la ideologia como falsa conciencia, dado que toda ideología a final de cuentas viene a ser una concepción antropológica y una visión de la realidad.

La "cuestión social" entendida a la luz de la teoría educativa riene salida y solución si se le da la preeminencia a la educación para converrirla en un proceso correcto de transf ormación social y desarrollo económico.

En diciembre de 1939 el Gral. Maximiliano Hernández Marrínez firmó el Decreto de Reforma de la Educación Nacional, luego de consultar a un grupo de educadores. La teoría de dicha reforma la diseñó Luis Escamilla, y los programas de trabajo fueron diseñados por Carlos
Monterrosa, Celestino Castro, Luis Samuel Cáceres y Rafael Ramírez.

En esta época la administración de la educación estaba adscrita al Ministerio de Relaciones Exteriores y Justicia, el cual contaba con una Subsecretaría de Instrucción Pública. Dicho programa de Reforma partía de nuevos programas de estudio bajo una estructura operativa de "jornalizaciones" y con un esquema en donde se partía de "propósitos" para proseguir con una metodología pedagógica decrolyana de "centros de observación", cuyo objetivo principal se definía así: "hacer de cada salvadoreño un hombre útil en el hogar, en la comunidad, en la nación y en el globo en general" 13 El programa de reforma se inició a finales de 1939 y finalizó en 1940, pero no llegó a incidir a educación media.

En la administración del Gral. Fidel Sánchez Hernández se Ilevó a cabo la Reforma Educativa de 1968, la cual estaba precedida de una época de bonanza económica, tras el auge comercial del café, del algodón y el azúcar en el mercado internacional.

En este contexto, se desarrollaba al interior de la UES un fuerte movimiento critico de izquierda, el cual comenzaba a ser reprimido con voracidad, a tal grado que el gobierno intolerante de Lemus ${ }^{14}$ llegó a maltratar físicamente al Rector y al Secretario General de la universidad, a perseguir a sus decanos con la orden de capturarlos vivos o muertos y a asesinar estudiantes; esto generó una respuesta universitaria, particularmente en el periódico "Opinión Estudiantil".

En el período de Lemus también se creó el Consejo Nacional de Educación por Decrero Ejecutivo fechado el 15 de febrero de 1957, en donde estaban representados los niveles educativos Universitario, Media y bachillerato, Primaria, Normal. Técnica, Agropecuaria, Física, Artística, Comercio, Prensa Nacional y Secretaría Coordinadora.

\section{La formación de formadores}

Con la caída de Lemus surge la Junta de Gobierno en octubre de 1959, la cual en el campo educativo desarrolla un plan de formación de maestros llamado "Bienio de la Educación Nacional”; para ello, se llevó a cabo una evaluación de los programas de estudio, en donde salió a flore la marginalidad de la alfabetización y la formación de formadores.

Cuantitativamente, este problema no podía resolverse en las Escuelas Normales, sino en la propia realidad de los educadores existentes; el diagnóstico indicó la necesidad de contar con 10,000 maestros más en los dos años pautados; al día siguiente de presentar el Plan la Junta de Gobierno 
fue enviada a lexilio, pero el Director de la Educación Normal se mantuvo en su puesto y se dedicó a fundar más Escuelas Normales en el país, llegando a tener 56 instituciones de esta indole.

entorno

entorino

entorno

entorno

entorno

entorno

entorno

entorno

entorno

entorno

entorno

entorno

entorno

entorno

entorno

entorno

entorno

entorno

entorno

entorno

entorno

entorno

entorno

entorno

entorno

entorno

entorno

entorno

entorno

entorno

entorno

entorno

entorno

entorno

entorno

entorno

entorno

entorno

entorno

entorno

entorno

entorno

entorno

entorno

entorno

entorno

entorino

En 1967 CONAPLAN presentó al Consejo de Ministros presidido por el Gral. Fidel Sánchez Hernández un estudio relacionado con los planes de acción que deberían formular cada ramo de la administración pública; ante esto, el Ministro de Educación integró una "Comisión de Reforma de la Educación"; el Ing. Román Mayorga Quiroz actuó como articulador entre COAPLAN y dicha Comisión; en la Comisión había representación de la empresa privada, TV Educativa, Ciudad Normal Alberro Masferrer, Diversas Direcciones del propio Ministerio y UNESCO². Seis macroindicadores constituían la base diagnóstica para el trabajo: disponibilidad per capita, vivienda, trabajo, salud, población y educación.

Para 1968 las tendencias del "desarrollismo" sustentadasen la Alianza por el progreso recorrían toda Latinoamérica; y sobre esta base se montaba la "Reforma de Béneke" con cuatro principios: 1) la educación es una empresa organizada para producir recursos humanos; 2) la educación es el método correcto de transformación social y desarrollo nacional; 3) la educación es el mejor medio de hacer que los seres humanos tengan nociones claras sobre el mundo físico y el mundo social; y 4) la educación es el método técnico para formar la personalidad humana, equilibrando sus poderes $y$ equilibrando su vigencia en el medio social.

Entre otra reformas particulares, era necesario contar con un nuevo marco legal, los cuales se encuentran en el "Documento 29": Ley general de Educación; Ley del Escalafón del Magisterio; Ley de Asistencia del Magisterio y Ley de la Profesión de Maestro.

Dos evaluaciones analizaron el impacto de la Reforma del 68, una en 1975 por AID, y otra en 1978 a modo de consulta, pero en realidad la mayor critica de parte de los secrores magisteriales a esta Reforma consistió en dos vertientes: una, que la reforma fue diseñada de modo descendente desde el gabinete y sin participación del gremio magisterial, otra, que existió una fuerte influencia de organismos internacionales.

Ya a finales de los ochenta, a juicio de ANDES 21 de Junio, comenzó un proceso de "Reforma Educativa Silenciosa", que giraba alrededor del programa SABE, con los cambios curriculares, y por las ideas de Municipalización de la Educación, ance esto existieron conatos de oposición, pero posteriormente se dio un giro radical.

El Consejo Ejecutivo de ANDES a inicios de los noventa, cambió su actitud, lo cual no fue fácil por su tradición, no obstance se entabló un profundo proceso de negociación con la nueva Ministra de Educación Lic. Cecilia Gallardo de Cano. lo cual fue criticado por algunos sectores radicales; de hecho ANDES había confrontado con todos los Ministros que habían pasado por ésta Cartera de Estado. ¿A causa de qué se da este cambio?

En primer lugar la finalización del conflicto con los Acuerdos de Paz en 1992 establecen un nuevo contexto socio-político. Sin embargo, hay que anotar que inmediatamence a los Acuerdos de Paz se llevó a cabo una huelga más incensa que las del 68 y 71, lo que parece contradictorio; dicha actividad, constituida por un paro de labores y por una huelga de hambre, se llevó a cabo porque ANDES consideraba que habian sido violados los derechos conquistados desde 1965 con mucha sangre, y con más de cuatrocientos maestros asesinados y desaparecidos durante estos duros tiempos.

La violación consistia en el proyecto de Municipalización de la Educación, lo cual ponía los puntos críticos de ANDES en una situación vulnerable, entre los cuales estaban: Bienestar Magisterial, Estabilidad laboral y Salario.

las exigencias de los diversos sectores magisteriales se han centrado en el docente y no en el alumno; en este sentido, todas las negociaciones han partido de un beneficio real para el maestro, y difícilmente los sindicatos han pensado en los beneficios de sus exigencias para el alumno y la comunidad
La Municipalización de la Educación consistía en la modernización del sistema educativo nacional con una modalidad de descentralización que fragmentaba el sistema educativo, transfiriendo la educación a los doscientos sesenta y dos Municipios del pais, la idea en teoría era discutible, pero en la práctica no se contaba con los recursos o condiciones en los Municipios para sostener el sistema educativo; estas ideas procedían de los sectores de planificación y de modelos de países América del Sur.

El gobierno en su momento supuso que ANDES había perdido la capacidad de convocatoria, movilización y respuesta, e intentó establecer esta nueva política; esta suposición estaba asociada al nuevo contexto de paz establecido por los 


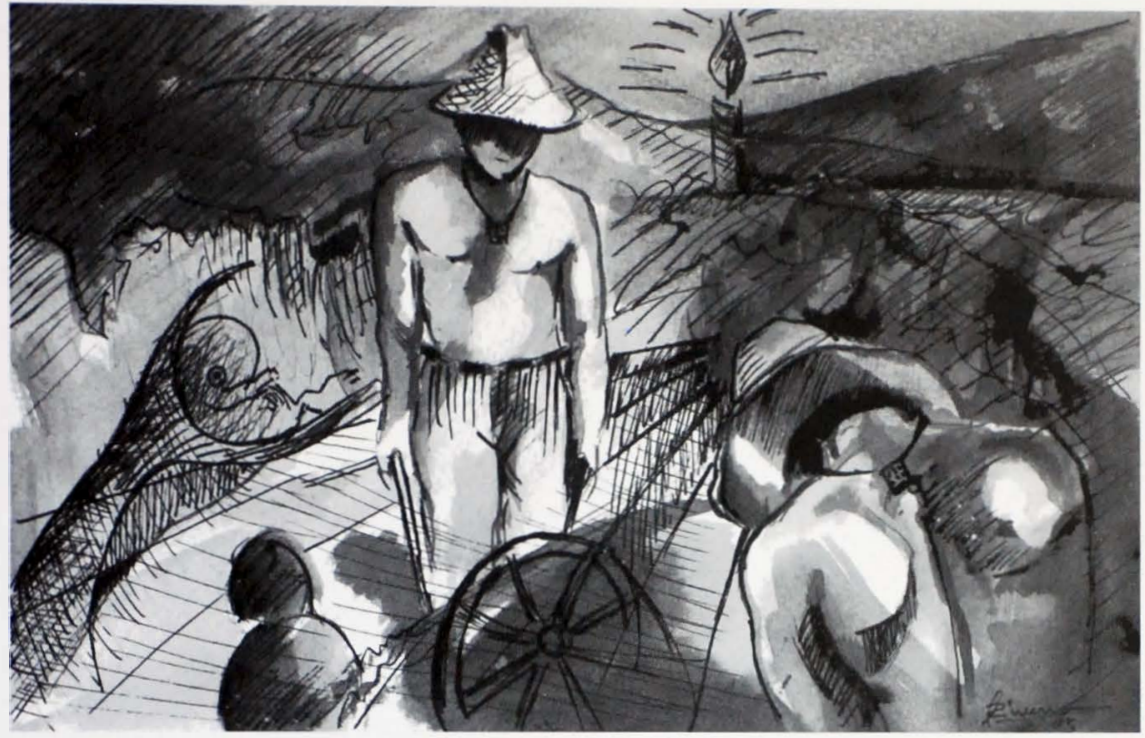

Acuerdos de Chapultepec, no obstante la respuesta de ANDES tuvo eco en el magisterio, y fue así como se establecieron las pautas para negociar.

El debate educativo, que inclusive hoy riene vigencia parte de una dicotomía sustantiva: ¿̨eforma o Transformación educativa?; para algunos pensadores educativos, el concepto de reforma responde más a una realidad que vive el mundo, y por ende el pais, es decir a las exigencias económicas de la globalización (gasto); en cambio transformación, responde más a un contexto de problemas sociales (inversión). Posiblemente las negociaciones establecidas entre el MINE D) y ANDES lograron conjugar ambas visiones -economicista y social- y a partir de una nueva concepción de participación y consulta, en donde se incluyó a ANDES se estableció un nuevo paradigma de diálogo entre el MINED) y el sector agremiado.

Posteriormente, se fragmentó ANDES y surgieron de su interior nuevas gremiales con otras visiones como Concertación Magisterial, SIMES, entre otros; también el grupo de directores de institutos nacionales CODINES. Pero las tensiones, negociaciones y diálogos se han mantenido como una constante. A juicio del MINED, otro tema central en el debate con las gremiales, es que las exigencias de los diversos sectores magisteriales se han centrado en el docente y no en el alumno; en este sentido, todas las negocia- ciones han partido de un beneficio real para el maestro, $y$ difícilmente los sindicatos han pensado en los beneficios de sus exigencias para el alumno y la comunidad.

¿Qué nos encontramosa nivel educativo en los noventa?; en primer lugar digamos que no existe -y si existicra es muy tenue- una filosofia de la educación que sustente un aparato reflexivo y lógico, a lo que apenas llegamos es a una teoría psicopedagógica - por cicrro mal aplicada- llamada "Cosntructivismo" a partir de las teorías evolutivas y cognoscitivas de Piaget, y su respectiva interpretación educariva por Kohlberg.

En segundo lugar, nos encontramos ante un marco de políticas educativas elaboradas bajo la óptica y criterio de cierros organismos internacionales, quienes condicionan los créditos de educación a expensas de seguir un modelo que apunta y apuesta a la educación básica con calidad y equidad. como estrategia para reducir los índices de pobreza, de hecho las politicas educativas son de gobierno y no de estado, no hay continuidad, ni mucho menos seriedad, son plataformas electorales.

No obstante, con este panorama: la brecha entre ricos y pobres, según los informes del PNUD sigue ampliándose; la inversión real en educación en los paisc:s subdesarrollados no supera el $2 \%$ del PIB, cuando se ha recomendado que

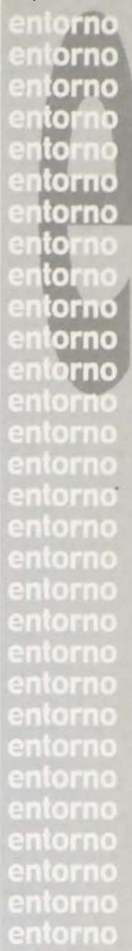

e

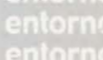

eriturits

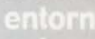

entorh

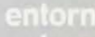

enlorn
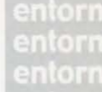

entorn

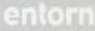

entorn

entorno

entorn.

entornt

entorne

entorne

enlorind

entorit

entorng

entornd
entornd

entorio

entorno

$\mathrm{N}^{\circ} .29$ 
dicha inversión debe superar el $4 \%$; más del $20 \%$ de la población centroamericana vive en analfaberismo; más del $40 \%$ de los niños/as están fuera del sistema educativo; los indices de repitencia, deserción y eficiencia superan el $30 \%$; los docentes de todo el sistema educarivo no poseen un rumbo reflexivo para autocomprender su gestión, y las generaciones de relevo, en materia profesional y docente son caóticas.

Además, no hay producción de ideas; la calidad docente esta en un devenir de entropía tras la desvaloración social y salarial de la profesión; las gremiales magisteriales se han quedado estáticas en un andamiaje de demandas simplemente salariales.

La educación sigue siendo un discurso demagógico como apuesta al desarrollo y al progreso para ingresar a la globalidad, bajo ciertos supuestos necesarios pero no absolutos, como el pensar que las "tecnologías educativas" son la panacea para ingresar al escenario global; los indicadores y tasas educativas carecen de validez y confiabilidad, dado que los censos demográficos están desactualizados y solo utilizan proyecciones que son cuestionables ante una dinámica demográfica verteginosa y altamente migratoria.

Constantemente se introducen "modas" educativas que emergen de concepciones empresariales, bajo el supuesto que serán análogamente exitosas como en la lógica del mercado.

La educación superior pública se ha aislado, dando paso a empresas académicas, además no se hace investigación, y la poca que se hace no cuenta con medios de difusión y aplicación; existen abundantes discursos de las Cumbres, UNESCO, UNICEF, etc., bajo el ideario de Educación Para Todos pero en la prácrica no se cristalizan. Se ha claborado un discurso "paidocentrico", pero en la realidad se continua con prácticas verticales $y$ tradicionales.

Las distribuciones presupuestarias de educación, en la región centroamericana, continua desbalanceada asignando más del $75 \%$ del presupuesto a un gran aparato burocrático y salarios, y el resto al tema de calidad e investigación.

No en vano, Daniel Filmus director de FLACSO Argentina, cree que la década de los 90 es otra década perdida en materia educativa; a partir de estas realidades, nos debemos preguntar: chemos aportado algo como académicos al problema de la filosofia de la educación?; ¿la crítica ha estado acompañada de alguna propuesta racional o por lo menos interesante?; ¿qué está pasando en otros ámbitos académicos sobreeste tema?; ¿qué es rescatable de la historia del pensamiento filosófico, para sustentar una filosofia educativa?; ¿qué tenemos que decir desde las Universidades de El Salvador $y$ desde nuestra propia realidad salvadoreńa para construir una filosofia educativa que responda a las necesidades actuales?

Con kant nos preguntamos: ¿qué debemos saber, esperar y hacer sobre este importante ?; con Marx nos preguntamos: ¿seguimos contemplando la realidad o la transformamos?; $y$ con nosotros mismos nos preguntamos: ‘cómo posibilitar la transformación?

\section{Bibliografía}

Zea, Leopoldo.; Aménica como descubrimiento: Universidad Central: Bogots. 1986

Galeano, Eduardo: Las Venes Abiereas de América Latına; Ed. Siglo XOL.

Barón Castro: La Población de El Saluador. Ed. UCA

David Browning; El Sulivador. La Tierra y El Hombre, Dirección de Publicaciones del MINED

Escamilla, Manucl; Una Educación enrer Dos Imperios y la Educación de Adulios. Dirección de Publicaciones e Impresos; 1990

\section{Citas y notas}

Con el término icónico se pretende indicar que no se trata de un ensayo histórieo con rigor cientifico. sino con apreciaciones de fuentes secundarias.

Manuel Luis Es amilla aborda este terna en "Una educación entre dos imperios y la educación de Adultos"

El Agustinismo Polírico consolida el principio de la espada al servicio de la coua. como un sometimiento del orden mundano a losobrenatural que viene implicaciones políticas directas en las acciones de la conquista y colonia.

Cfr. ZEA. Leopoldo.: América como descubrimiento; Universidad Central; Bogota. 1986

Cfr. Galeano, Eduardo; Las Venas Abiertas de América Latina: Ed. Siglo XXI: pag 64

Ver Barón Castro "La Población de El Salvador"; Ed. UCA pag. 156 y David Browning "El Salvador, la Tierra y El Hombre" Dirección de l'ublicaciones del MINED, pags. 77-78.

Cfr. Galeano, Eduardo; Op. Cit. Pag. 172

- A la base de esta concepción se encuentran los "signos extraeclesiales" del protestantismo Luterano y Calvinista, en donde la prosperidad material es un signo salvifico

Las obras educativas más importantes de Dewey son: Escuela y Sociedad, Como Pensamos, Democracia y Educación, Libertad y Cultura, La Educación de Hoy, y Lógica (teoría de la investigación)

${ }^{10}$ Escamilla. Manuel; Una Educación entre Dos Imperios y la Educación de Adultos: Dirección de Publicaciones e Impresos: 1990; pag. 95

"Los maestros son: Francisco Gamboa.José Núriez, Víctor Dubarry y Marcial Cruz

${ }^{12}$ Mariátegui oVictor Raúl Haya de la Torre, definen este concepto eomo una sociedad en problemas a partir del análisis maxista.

13 $\mathrm{C} f$. Decreto No $17 \mathrm{del} 8$ de diciembre de 1939

"Lemus odiaba al estudiantado porque habla sido ridiculizado en los desfiles bufos

Nota: Esta Ley se encuentra en la Recopilación de Leyes de las Indias

Nombre de la Comisión: Mauricio Borgonovo Pohl (ASI), Irma Lanza (TV Educativa), GilbertoAguilar Aviles (Ciudad Normal), Julia Rosa Manzano (Ténieopedagógicos); Manuel Luis Escamilla (Universidad); Bruno Stglizt (UNESCO), y Román Mayorga Quiroz (CONAPLAN) 